\title{
Preoperative Diagnosis predicts Outcomes in Patients with Concurrent Medullary and Papillary Thyroid Carcinoma
}

\author{
${ }^{1}$ Toni Beninato, ${ }^{2}$ Wouter P Kluijfhout, ${ }^{3}$ Frederick T Drake, ${ }^{4}$ Wen T Shen, ${ }^{5}$ Insoo Suh, ${ }^{6}$ Quan-Yang Duh \\ ${ }^{7}$ Orlo H Clark, ${ }^{8}$ Jessica E Gosnell
}

\begin{abstract}
Aim: This study examined patients with concurrent medullary thyroid carcinoma (MTC) and papillary thyroid carcinoma (PTC) with the primary objective of identifying factors that can determine the dominant subtype that will dictate recurrence.
\end{abstract}

Materials and methods: The cancer registry at our tertiary care referral center was reviewed to identify all patients from 1995 to 2015 who had been diagnosed with both MTC and PTC on initial total thyroidectomy. Patient demographic, pathology, and recurrence data were collected and reviewed.

Results: Nineteen patients met the inclusion criteria. Seventeen patients had separate foci of MTC and PTC, and two patients had mixed tumors of medullary and follicular or medullary and the follicular variant of PTC. Thirteen patients had a preoperative diagnosis of MTC, and all 13 had MTC as the higher stage tumor on final pathology. Of these, eight patients had recurrent disease, all of which recurred as MTC. In the six patients with concurrent MTC and PTC who did not have MTC as the preoperative diagnosis, the PTC was the higher stage tumor. Only one patient in this group recurred with PTC, none with MTC. No patients have had recurrent disease that was a different subtype from their preoperative diagnosis or the higher stage tumor.

Conclusion: The concurrent findings of MTC and PTC in the same patient may result in challenging patient counseling, management, and follow-up. In this series of 19 patients with concurrent PTC and MTC, the subtype of recurrence in all 9 patients with recurrent disease was determined by the preoperative diagnosis and higher stage tumor.

Clinical significance: The incidental discovery of a second subtype of differentiated thyroid cancer should not alter management of the primary tumor. Patients should be treated in accordance with the preoperative diagnosis and higher stage tumor.

\footnotetext{
${ }^{1,3,5}$ Assistant Professor, ${ }^{2}$ Resident, ${ }^{4,8}$ Associate Professor ${ }^{6}$ Professor, ${ }^{7}$ Professor Emeritus

${ }^{1}$ Department of Surgery, Weill Cornell Medicine, Brooklyn, New York, USA

${ }^{2}$ Department of Surgery, University Medical Center, Utrecht Netherlands

${ }^{3}$ Department of Surgery, Boston University School of Medicine Boston, Massachusetts, USA

${ }^{4-8}$ Department of Surgery, University of California, San Francisco, California, USA

Corresponding Author: Jessica E Gosnell, Associate Professor, Department of Surgery, University of California San Francisco, California, USA, Phone: +4158857616 , e-mail: jessica.gosnell@ucsfmedctr.org
}

Keywords: Cohort study, Medullary thyroid cancer, Mixed thyroid tumors, Papillary thyroid cancer.

How to cite this article: Beninato T, Kluijfhout WP, Drake FT, Shen WT, Suh I, Duh QY, Clark OH, Gosnell JE. Preoperative Diagnosis predicts Outcomes in Patients with Concurrent Medullary and Papillary Thyroid Carcinoma. World J Endoc Surg 2017;9(3):94-99.

Source of support: Nil

Conflict of interest: None

\section{INTRODUCTION}

The simultaneous occurrence of MTC and PTC was first reported by Lamberg et $\mathrm{al}^{1}$ and remains a rare finding. The coexistence of these tumor subtypes in the same thyroid can manifest in two ways: As distinct foci of MTC and PTC separated by normal thyroid tissue, or as a single tumor with histologic characteristics of both subtypes. This finding is of particular interest because the cells from which these tumors derive have differing embryologic origins. The MTC develops from the parafollicular C-cells of the thyroid that have their origin in the neural crest. In contrast, PTC develops from the follicular cells of the thyroid and are derived from endoderm. ${ }^{1}$

There are several theories as to how two embryologically unrelated cell types can simultaneously become neoplastic. The "stem cell" hypotheses suggest the existence of a common stem cell ancestor for follicular and parafollicular cells either in the thyroid or in the ultimobranchial remnant. ${ }^{2,3}$ Other hypotheses suggest simultaneous neoplastic transformation of the two subtypes, either spontaneously or by a common mutation or rearrangement in the rearranged during transfection (RET) gene. - $^{4-8}$

The finding of two separate tumors with distinct clinical courses and treatment options may prove to be challenging for clinicians. Most of the available literature on patients with MTC and PTC are case reports without data on long-term outcomes..$^{1-3,7,9-23}$ Consequently, there is little data available to clinicians about how to predict which tumor subtype will be most at risk for recurrence. There are a few larger case series that have concluded that MTC will be the dominant tumor, and that the concurrent PTC represents an incidental finding with little bearing 
Preoperative Diagnosis predicts Outcomes in Patients

on the outcome. ${ }^{24-26}$ However, population-based studies have shown a better prognosis for patients with both MTC and PTC than for MTC alone. ${ }^{27}$ Therefore, in this study, we examine a single-institution's experience with patients with concurrent MTC and PTC with the primary objective of identifying factors that can determine the dominant subtype that will dictate recurrence.

\section{MATERIALS AND METHODS}

The cancer registry at our tertiary care referral center was reviewed to identify all patients from 1995 to 2015 who had been diagnosed with simultaneous MTC and PTC on initial total thyroidectomy. A retrospective chart review was completed to collect information, such as age, sex, preoperative diagnosis via ultrasound-guided needle biopsy, results of genetic testing, and extent of surgery. Pathology reports were reviewed to determine tumor size, subtype(s), multifocality, and aggressive features, such as extrathyroidal extension, lymphovascular invasion, positive surgical margin, lymph node metastases, and extranodal extension of tumor. Details on postoperative treatment, such as radioactive iodine and chemotherapy were collected. Follow-up data including recurrence, disease status, and length of follow-up were also reviewed.

Statistical analysis was performed using Statistical Package for the Social Sciences version 22.0. Student's t-test was used to analyze continuous variables. For all analyses, a p-value of $<0.05$ was considered significant. This study was done with the approval of the Committee on Human Research, which is the institutional review board at the University of California, San Francisco.

\section{RESULTS}

From 1995 to 2015, 19 patients had concurrent MTC and PTC on final pathology after thyroid surgery. Seventeen of these patients had distinct separate foci of "classic" MTC and PTC, one patient had classic PTC and a mixed medullary and follicular carcinoma, and one patient had a solitary mixed medullary and follicular variant of papillary thyroid carcinoma (fvPTC). Totally, 10 (52.6\%) patients were men, and the mean age at initial surgery was 53 years (35-69 years). Five patients (35.7\%) of the 14 who underwent genetic testing had mutations of the RET gene that were consistent with multiple endocrine neoplasia type 2A (MEN2A).

\section{Patients with a Preoperative Diagnosis of MTC}

Thirteen patients had a preoperative diagnosis of MTC. Totally, 7 (53.8\%) patients were male and the mean age was 51 years (35-65). All 13 patients underwent genetic
Table 1: Characteristics of the tumors found in the 13 patients with a preoperative diagnosis of MTC

\begin{tabular}{lll}
\hline & MTC & PTC \\
\hline Median tumor size $(\mathrm{cm})$ & $1.2(0.45-7.0)$ & $0.3(<0.1-1.3)$ \\
Aggressive tumor characteristics & & \\
Extrathyroidal extension & $3(27.3 \%)$ & 0 \\
Tumor at inked margin & $2(18.2 \%)$ & $1(7.6 \%)$ \\
Multifocal disease & $5(45.5 \%)$ & $4(30.7 \%)$ \\
Lymphovascular invasion & $3(27.3 \%)$ & 0 \\
Number of patients with tumor & 7 & 2 \\
$\begin{array}{l}\text { subtype in lymph nodes } \\
\text { Patients with subtype in recurrence }\end{array}$ & 8 & 0 \\
$\begin{array}{l}\text { Patients with subtype of distant } \\
\text { metastases }\end{array}$ & 3 & 0 \\
\hline
\end{tabular}

a11/13 patients had primary tumor details for MTC, all 13 had details for PTC

testings and four patients had mutations consistent with MEN2A. The following operations were performed: Six patients underwent a total thyroidectomy with central neck dissection and seven underwent total thyroidectomy with central and lateral neck dissection. The tumor characteristics of the MTCs and PTCs in these patients are listed in Table 1. All except one patient with a preoperative diagnosis of MTC had papillary microcarcinoma.

Pathology results included the following. All 13 patients had at least one lymph node removed at the time of the initial procedure. Eight patients $(61.5 \%)$ had positive metastatic lymph nodes. Six had only MTC in the lymph nodes (two of whom had extranodal extension), one patient had only PTC in the lymph nodes, and one patient had 10/17 lymph nodes with MTC and 1/17 lymph nodes with PTC.

For patients with a preoperative diagnosis of MTC, eight patients (61.5\%) had recurrent disease, all eight of which recurred as MTC only. Five patients had recurrence in the locoregional lymph nodes, four of whom had a second surgery. The fifth patient declined reoperation. Three patients developed distant metastasis of MTC: One in the mediastinal lymph nodes, and two in the liver. Two patients underwent treatment with tyrosine kinase inhibitors and one had radiation treatment. None of the patients who presented with MTC initially had recurrence of their PTC. The median follow-up in this group was 31 months (0.5-233 months).

\section{Patients without MTC as a Preoperative Diagnosis}

In the six patients who presented with a diagnosis other than MTC, four had a preoperative diagnosis of PTC, one had a fine needle aspiration that was "suspicious for malignancy", and the other patient presented with 
Table 2: Characteristics of the tumors found in the six patients without a preoperative diagnosis of MTC

\begin{tabular}{|c|c|c|c|c|}
\hline & $\operatorname{MTC}(n=4)$ & $\operatorname{PTC}(n=5)$ & $\begin{array}{l}\text { Mixed medullary } \\
\text { and fVPTC }(n=1)\end{array}$ & $\begin{array}{l}\text { Mixed medullary } \\
\text { and FTC }(n=1)\end{array}$ \\
\hline Mean tumor size $(\mathrm{cm})$ & $0.6(0.4-1.4)$ & $1.6(1.3-6.5)$ & 8.0 & 2.5 \\
\hline \multicolumn{5}{|l|}{ Aggressive tumor characteristics } \\
\hline Extrathyroidal extension & 0 & $2(40 \%)$ & 0 & 0 \\
\hline Tumor at inked margin & 0 & 0 & 0 & 0 \\
\hline Multifocal disease & $2(33.3 \%)$ & $3(60 \%)$ & $1(100 \%)$ & 0 \\
\hline Lymphovascular invasion & 0 & $1(20 \%)$ & 0 & 0 \\
\hline Number of patients with tumor subtype in lymph nodes & 0 & 2 & 1 & 0 \\
\hline Patients with subtype in recurrence & 0 & 1 & 0 & 0 \\
\hline Patients with subtype in distant metastases & 0 & 0 & 0 & 0 \\
\hline
\end{tabular}

tertiary hyperparathyroidism and a previously benign thyroid biopsy. Three (50\%) patients were men and the mean age was 56 years (41-69). With regard to operative approach, two patients had total thyroidectomy, three had a total thyroidectomy with central neck dissection, and one had a total thyroidectomy with central and lateral neck dissection. The tumors diagnosed in these patients and their characteristics are listed in Table 2. Four patients had classic PTC and "classic" MTC, one had classic PTC and a mixed medullary and follicular tumor, and one patient had a solitary tumor of mixed medullary and fvPTC.

On pathologic evaluation, every patient had at least one lymph node removed at the time of the initial procedure. Three $(50 \%)$ patients had positive metastatic lymph nodes at the time of initial surgery. Two of these were classic PTC and one was the mixed medullary and fvPTC. One patient had extranodal extension.

After a median follow-up of 23.5 months (4-135), one patient had recurrent PTC and underwent reoperative neck dissection. This patient also received external beam radiation.

Of note, one patient in this group had a thyroid nodule that was diagnosed preoperatively as PTC, but also had a first-degree family member who was recently found to have a RET C634G mutation consistent with MEN2A and later also tested positive for this mutation. This patient had two foci of PTC and two foci of MTC on final pathology, and 7/23 lymph nodes positive for PTC. None of the patients who presented with nonmedullary cancer had recurrence of their MTC.

\section{Combined Recurrence Data}

The preoperative diagnosis, stage of each tumor at the time of diagnosis, and subtype of tumor that recurred are listed in Table 3. Overall, 11/19 (57.9\%) patients had metastatic disease in the locoregional lymph nodes at the time of surgery. Nine patients (47.4\%) had recurrent disease and three $(15.8 \%)$ had distant metastases. In the
Table 3: Preoperative diagnosis, stage of each tumor, and subtype of recurrence for the 19 patients in the study

\begin{tabular}{|c|c|c|c|c|}
\hline Patient & $\begin{array}{l}\text { Preoperative } \\
\text { diagnosis }\end{array}$ & $\begin{array}{l}\text { Medullary } \\
\text { stage }\end{array}$ & $\begin{array}{l}\text { Papillary } \\
\text { stage }\end{array}$ & Recurrence \\
\hline 1 & Medullary & T3N1bM0 & T1aN0M0 & Medullary \\
\hline 2 & Medullary & T1bN0M0 & T1aNOMO & None \\
\hline 3 & Medullary & T3N0M0 & T1aN0M0 & None \\
\hline 4 & Medullary & T3N1bM1 & T1aNOMO & Medullary \\
\hline 5 & Medullary & T1bN1bM0 & T1aN1aM0 & None \\
\hline 6 & Medullary & TON1aM0 & T1aN0M0 & Medullary \\
\hline 7 & Medullary & T1bN0M0 & T1aN0M0 & Medullary \\
\hline 8 & Medullary & T3NOMO & T1aNOMO & None \\
\hline 9 & Medullary & T1aN1M0 & T1aN0M0 & Medullary \\
\hline 10 & Medullary & T3N1bM0 & T1bN0M0 & Medullary \\
\hline 11 & Medullary & T1aN0M0 & T1aN0M0 & None \\
\hline 12 & Medullary & TxN1aM0 & T1aN0M0 & Medullary \\
\hline 13 & Medullary & T3N0M1 & T1aN1M0 & Medullary \\
\hline 14 & Papillary & $\mathrm{T}_{2} \mathrm{NOMO}^{\mathrm{a}}$ & T3NOMO & Papillary \\
\hline 15 & Papillary & T1aN1M0 & T3N1bM0 & None \\
\hline 16 & Papillary & T1aN0M0 & T1bN0M0 & None \\
\hline 17 & Papillary & T3N1aM0 ${ }^{b}$ & T3N1aM0 & None \\
\hline 18 & $\begin{array}{l}\text { Suspicious for } \\
\text { malignancy }\end{array}$ & T1bN0M0 & T1bN0M0 & None \\
\hline 19 & $\begin{array}{l}\text { Tertiary hyper- } \\
\text { parathyroidism }\end{array}$ & T1aNOM0 & TxN1aM0 & None \\
\hline
\end{tabular}

${ }^{a}$ Mixed medullary and follicular thyroid carcinoma; bolitary mixed medullary and papillary tumor

patients who presented with MTC, eight patients had recurrent disease, all of which was MTC. In these patients, the MTC was the largest tumor in 6/8 (75\%) patients, and had the most foci in $5 / 8(62.5 \%)$ patients. The MTCs in the patients who presented with MTC first were significantly larger than in those who did not present with MTC (1.2 vs $0.6 \mathrm{~cm}, \mathrm{p}=0.02)$. There was no difference in the size of PTCs in those who presented with MTC first vs not (0.3 vs 1.6, $\mathrm{p}=0.16)$. In the patients who presented with PTC or other, one had recurrent PTC. This patient had a multifocal $6.5 \mathrm{~cm}$ PTC and a $2.5 \mathrm{~cm}$ mixed MTC/fvPTC. In all patients with recurrences, the higher stage tumor at the time of initial surgery, which was also consistent with the preoperative diagnosis, was the subtype that recurred. 


\section{DISCUSSION}

In this study, we review a single institution's experience with patients with concurrent MTC and PTC to attempt to identify factors that can predict the patients' clinical course. We examined 19 patients with evidence of both MTC and PTC (or a mixed tumor) on final pathology and divided them based on their preoperative diagnosis. In the nine patients with recurrent disease (eight with MTC and one with PTC), the subtype of recurrence was consistent with the preoperative diagnosis and with the subtype with the more advanced stage at the time of initial surgery. Recurrence did not appear to be influenced by the subtype of the largest tumor or most foci. This contrasts with previous findings that PTC in the setting of MTC is always an incidental finding and an innocent bystander in the disease course. ${ }^{25}$

In addition to the many case reports of patients with MTC and PTC, there have been several larger studies that reviewed this entity. The first was by Biscolla et al, ${ }^{24}$ who reviewed 27 patients with MTC and PTC and found that the incidence of PTC in patients with MTC (13.8\%) was higher than that seen with Grave's disease (5.1\%) and multinodular goiter (6.4\%). While they excluded older age of patients and increased diagnostic scrutiny as an explanation for the higher incidence of PTC in MTC than in other benign thyroid pathologies, they did not offer further hypotheses to explain this finding. They concluded that the clinical behavior of MTC was not influenced by the presence of a concomitant PTC.

Two studies further examined the incidence of PTC in patients with MTC. Kim et $\mathrm{al}^{25}$ published a series of 10 patients with MTC and PTC. In their study, the incidence of PTC in patients with MTC was 19\%, which was similar to that seen in Graves' disease (15\%) and follicular thyroid carcinoma (19\%) at their institution. They also found that the patients with MTC and PTC were significantly older than those with MTC alone, which they postulated was responsible for the increased incidence of PTC seen in these patients. Similar to Biscolla et al, ${ }^{24}$ they concluded that because the incidence of PTC was similar across the different pathologies, cases of concurrent MTC and PTC are reflections of coincidence. Machens and Dralle 26 published their series of 26 patients with MTC and PTC. They found lower incidences of PTC in patients with MTC $(3.6 \%)$ than the previous studies, and also found that the incidence of simultaneous MTC and PTC has been increasing over time, which they attributed to either greater pathologic scrutiny or environmental changes. Neither study examined recurrence data or outcomes in their patients.

Wong et $\mathrm{al}^{27}$ performed a population-level analysis of 162 patients with simultaneous medullary and differentiated thyroid cancer (DTC) from the Surveillance, Epidemiology, and End Results database. They found that the incidence of DTC with MTC had increased over time from $2.7 \%$ of MTCs (1988-1997) to 7.5\% from 1998 to 2002 to $12.3 \%$ from 2003 to 2008 , which was consistent with what was found by Machens and Dralle. ${ }^{26}$ Overall, simultaneous MTC and DTC was found in 9.5\% of all patients with MTC. They did not compare the incidence of DTC in MTC with that in other pathologies. The MTC was diagnosed first in $67.9 \%$ of patients. Patients diagnosed with DTC first had smaller mean MTC tumor sizes and those diagnosed with MTC first had similar tumor sizes compared with those with MTC alone. This is similar to our study in that the size of the MTC when diagnosed first was larger than that when MTC was not the preoperative diagnosis.

Wong et $\mathrm{al}^{27}$ also examined survival in these patients. Disease-specific survival rates were higher for simultaneous MTC/DTC than for MTC alone. They found no differences in age at diagnosis between patients with MTC/DTC and MTC alone, which argues against increasing age as the reason for the increased incidence of DTC. They concluded that patients with MTC/DTC are diagnosed earlier in tumor development than those with MTC alone, which leads to the trend in better prognosis and downstaging of the MTC. They suggested that both tumors should be treated according to their individual stage and current guidelines, and that MTC prevails in driving survival and should be treated aggressively.

The studies by Biscolla et al, ${ }^{24} \mathrm{Kim}$ et al, ${ }^{25}$ and Machens and Dralle ${ }^{26}$ all attributed the finding of MTC and PTC in the same thyroid to coincidence. Biscolla further concluded that the presence of the PTC did not influence the MTC in individual patients. However, Wong et $\mathrm{al}^{27}$ saw improved survival in patients with both MTC and DTC compared with MTC alone, which may imply a positive influence of the DTC on the outcome of the MTC in the population as a whole.

In our study, the preoperative diagnosis influenced the outcome. The preoperative diagnosis was also always the higher stage tumor, which was usually MTC, in concurrence with other previously published studies. However, in contrast to previous studies, in patients who were diagnosed with PTC or had PTC as the higher stage tumor, their outcome was influenced more by the PTC. There was only one recurrence in our six patients who fell into this group, which is reflective of the favorable overall outcome in patients with PTC. This one recurrence, however, is evidence that PTC is not always an innocent bystander and can influence the clinical course in these patients. This may also explain why Wong et al showed improved survival in patients with DTC and 
MTC together. The other third of patients in their study who had the DTC diagnosed first may have had a higher stage DTC than MTC and, therefore, a clinical course consistent with that of the more favorable prognosis of DTC.

There are several limitations to our study, namely that it is a single institution's experience with a relatively rare finding and may be biased by sample size and referral patterns. Median follow-up was also around 2 years, which may be enough time to capture some MTC recurrences, but is relatively short to capture potential PTC recurrences.

\section{CONCLUSION}

In summary, this study showed that in patients with both MTC and PTC, the subtype of preoperative diagnosis or the higher stage tumor is the same as the subtype seen in recurrent disease. This study is the first to show that PTC is not always an incidental finding with no influence on the outcome when seen with MTC, and its occasional higher stage at presentation may even be implicated in the improved survival seen in the population of these patients as a whole. We concur with prior recommendations that each tumor subtype should be treated according to its stage at presentation.

\section{CLINICAL SIGNIFICANCE}

The incidental discovery of a second subtype of DTC should not alter management of the primary tumor. Patients should be treated in accordance with the preoperative diagnosis and higher stage tumor.

\section{REFERENCES}

1. Lamberg BA, Reissel P, Stenman S, Koivuniemi A, Ekbolm M, Mäkinen J, Franssila K. Concurrent medullary and papillary thyroid carcinoma in the same thyroid lobe and in siblings. Acta Med Scand 1981 Jan;209(5):421-424.

2. Ljungberg O, Ericsson UB, Bondeson L, Thorell J. A compound follicular-parafollicular cell carcinoma of the thyroid: a new tumor entity? Cancer 1983 Sep;52(6):1053-1061.

3. Lax SF, Beham A, Kronberger-Schönecker D, Langsteger W, Denk H. Coexistence of papillary and medullary carcinoma of the thyroid gland-mixed or collision tumour? Clinicopathological analysis of three cases. Virchows Arch. 1994 May;424(4):441-447.

4. Volante M, Papotti M, Roth J, Saremaslani P, Speel EJ, Lloyd RV, Carney JA, Heitz PU, Bussolati G, Komminoth P. Mixed medullary-follicular thyroid carcinoma. Molecular evidence for a dual origin of tumor components. Am J Pathol 1999 Nov;155(5):1499-1509.

5. Fugazzola L, Cerutti N, Mannavola D, Ghilardi G, Alberti L, Romoli R, Beck-Peccoz P. Multigenerational familial medullary thyroid cancer (FMTC): evidence for FMTC phenocopies and association with papillary thyroid cancer. Clin Endocrinol (Oxf) 2002 Jan;56(1):53-63.
6. MelilloRM,Cirafici AM,DeFalco V, BellantoniM,ChiappettaG, Fusco A, Carlomagno F, Picascia A, Tramontano D, Tallini G, et al. The oncogenic activity of RET point mutants for follicular thyroid cells may account for the occurrence of papillary thyroid carcinoma in patients affected by familial medullary thyroid carcinoma. Am J Pathol 2004 Aug;165(2):511-521.

7. Shah K, Zena M, Adickes ED, Anderson RJ. Case of concurrent MTC and PTC in a patient with a germline RET mutation. Endocr Pathol 2015 Sep;26(3):279-283.

8. Shifrin AL, Xenachis C, Fay A, Matulewicz TJ, Kuo YH, Vernick JJ. One hundred and seven family members with the rearranged during transfection V804M proto-oncogene mutation presenting with simultaneous medullary and papillary thyroid carcinomas, rare primary hyperparathyroidism, and no pheochromocytomas: is this a new syndrome-MEN 2C? Surgery 2009 Dec;146(6):998-1005.

9. Gero MJ, Lipper S, Chernys AE, Silver L. Medullary and papillary carcinomas occurring as a collision tumor: report of a case. Clin Nucl Med 1989;14(3):171-174.

10. Kobayashi K, Teramoto S, Maeta H, Ishiguro S, Mori T, Horie Y. Simultaneous occurrence of medullary carcinoma and papillary carcinoma of the thyroid. J Surg Oncol 1995 Aug;59(4):276-279.

11. Merchant FH, Hirschowitz SL, Cohan P, Van Herle AJ, Natarajan S. Simultaneous occurrence of medullary and papillary carcinoma of the thyroid gland identified by fine needle aspiration. A case report. Acta Cytol 2002 JulAug;46(4):762-766

12. Cupisti K, Raffel A, Ramp U, Wolf A, Donner A, Krausch M, Eisenberger CF, Knoefel WT. Synchronous occurrence of a follicular, papillary and medullary thyroid carcinoma in a recurrent goiter. Endocr J 2005 Apr;52(2):281-285.

13. Nicolas MM, Neto AG, Luna MA. Concurrent papillary and medullary thyroid carcinoma. Arch Pathol Lab Med 2005 Mar;129(2):264-265.

14. Rossi S, Fugazzola L, De Pasquale L, Braidotti P, Cirello V, Beck-Peccoz P, Bosari S, Bastagli A. Medullary and papillary carcinoma of the thyroid gland occurring as a collision tumour: report of three cases with molecular analysis and review of the literature. Endocr Relat Cancer 2005 Jun;12(2):281-289.

15. Younes N, Shomaf M, Al Hassan L. Simultaneous medullary and papillary thyroid carcinoma with lymph node metastasis in the same patient: case report and review of the literature. Asian J Surg 2005 Jul;28(3):223-226.

16. Rios A, Rodriguez JM, Ferri B, Balsalobre MD, Parrilla P. Association of medullary and differentiated thyroid carcinomas. Otolaryngol Head Neck Surg 2006 Sep;135(3):473-475.

17. Dionigi G, Castano P, Bertolini V, Boni L, Rovera F, Tanda ML, Capella C, Bartalena L, Dionigi R. Simultaneous medullary and papillary thyroid cancer: two case reports. J Med Case Rep 2007 Nov; $1: 133$.

18. López JI, Ruiz A, Ugarte E, Paja M, Ereño C, Gaafar A. Synchronous occurrence of macroscopic papillary and medullary thyroid carcinomas. Hematol Oncol Stem Cell Ther 2008 Jul;1(3):193-196.

19. Griffith C, Zhang S, Mukhopadhyay S. Synchronous metastatic medullary and papillary thyroid carcinomas in a patient with germline RET mutation: case report, molecular analysis, and implications for pathogenesis. Endocr Pathol 2010 Jun;21(2):115-119. 
20. Erhamamci S, Reyhan M, Kocer NE, Nursal GN, Torun N, Yapar AF. Simultaneous occurrence of medullary and differentiated thyroid carcinomas. Report of 4 cases and brief review of the literature. Hell J Nucl Med 2014 May-Jun;17(2):148-152.

21. Fibbi B, Pinzani P, Salvianti F, Rossi M, Petrone L, De Feo ML, Panconesi R, Vezzosi V, Bianchi S, Simontacchi G, et al. Synchronous occurrence of medullary and papillary carcinoma of the thyroid in a patient with cutaneous melanoma: determination of BRAFV600E in peripheral blood and tissues. Report of a case and review of the literature. Endocr Pathol 2014 Sep;25(3):324-331.

22. Ateşpare A, Çaliş AB, Çelik Ö, Yener N, Vural Ç. Concurrent medullary and papillary carcinoma of thyroid. Kulak Burun Bogaz Ihtis Derg 2015 Jul;25(3):170-173.

23. Mazeh H, Orlev A, Mizrahi I, Gross DJ, Freund HR. Concurrent medullary, papillary, and follicular thyroid carcinomas and simultaneous cushing's syndrome. Eur Thyroid J 2015 Mar;4(1):65-68.
24. Biscolla RP, Ugolini C, Sculli M, Bottici V, Castagna MG, Romei C, Cosci B, Molinaro E, Faviana P, Basolo F, et al Medullary and papillary tumors are frequently associated in the same thyroid gland without evidence of reciprocal influence in their biologic behavior. Thyroid 2004 Nov;14(11): 946-952.

25. Kim WG, Gong G, Kim EY, Kim TY, Hong SJ, Kim WB, Shong YK. Concurrent occurrence of medullary thyroid carcinoma and papillary thyroid carcinoma in the same thyroid should be considered as coincidental. Clin Endocrinol (Oxf) 2010 Feb;72(2):256-263.

26. Machens A, Dralle H. Simultaneous medullary and papillary thyroid cancer: a novel entity? Ann Surg Oncol 2012 Jan;19(1):37-44.

27. Wong RL, Kazaure HS, Roman SA, Sosa JA. Simultaneous medullary and differentiated thyroid cancer: a populationlevel analysis of an increasingly common entity. Ann Surg Oncol 2012 Aug;19(8):2635-2642. 